\title{
The Development of Static Load Testing Instrument for Piles Based on the Internet of Things
}

\author{
Li Jie-ming ${ }^{1, a}$, Huang Xiao-dan ${ }^{1, b}$, Mei Min-zhang ${ }^{1, c}$ \\ ${ }^{1}$ Guangzhou Institute of Building Science Co., Ltd., Guangzhou 510440 \\ a332338048@qq.com, b2528584758@qq.com, ${ }^{\circ} 574824858 @ q q . c o m$
}

\begin{abstract}
Keywords: Static load test, axial compressive bearing capacity of piles, internet of things
Abstract. An IoT-based wireless intelligent testing instrument is developed for static load test of piles, and it is applied to a field test in order to measure the axial compressive bearing capacity of a pile, while traditional wired devices are also deployed in the same test for comparison. The comparison shows that the wireless intelligent testing instrument can be installed without wiring, and the non-contact, high-accuracy displacement measuring method is suitable for the static load test of piles. Both of the test results of the wireless and the wired testing instrument indicate that the settlement rate of the tested pile satisfies the relative stable condition proposed by the testing code, which implies that the tested pile is qualified for practical use.
\end{abstract}

\section{Introduction}

The bearing capacity of piles is an important factor to evaluate the piles' quality. As the most accurate and reliable way to determine the bearing capacity of piles, static load test is wildly used in pile quality assessment $[1,2]$.

Traditionally, the loading and unloading process in the test was totally conducted manually, which had made the test very risky, meanwhile, the manual data collecting had reduced the reliability of the result. Therefore, as early as the 1980s, China has started to develop the equipment for static load test of piles [1]. Through decades of research and investment, in most of the static load tests at present, the loading process, data collecting and stability judgment is controlled by the testing instrument automatically. However, almost every testing instrument requires cable for power supply and data transfer, limiting the amount of the sensors for pile settlement observation, and sometimes the arrangement of wire can be very complicated.

With the development of the Internet of Things Technology, the testing and monitoring instruments is becoming wireless and more intelligent. In some area, wireless intelligent instruments have been applied to formwork monitoring, curtain wall testing and bridge health monitoring [3-5]. As for the static load testing of piles, the JCQ-503C static load testing instrument developed by the Xuzhou Institute of Construction and Engineering has realized the wireless connection between the domain terminal and the data transfer unit (DTU), but it still takes wire to connect the DTU and the sensors. Wang[6] had given a solution of wireless data transfer according to the communication demand of static load test of piles, and $\mathrm{Yu}[7,8]$ had designed a wireless static load testing system based on PSoC and $\mathrm{CyFi}$, however, neither of these achievements was examined by practical test.

In this paper, a wireless intelligent static load testing instrument is developed and applied in the field test. The testing result is compared with one of the most widely used ordinary wired testing instrument, accumulating practical experience for the application and promotion of wireless intelligent static load testing instrument.

\section{Static Load Test for Piles for Piles under Axial Compressive Load}

In the static load test for a pile under axial compressive load, one or more hydraulic jacks are placed between the pile head and the counterforce equipment, the hydraulic jacks will gradually lift the counterforce equipment and hence the load of the counterforce equipment will be applied to the pile. The counterforce equipment can be weight platform (Fig 1) or anchor-pile beam (Fig 2). The 
settlement of the pile will be observed during the test in order to determine the axial compressive bearing capacity of the pile.

According to the Chinese code for testing of building foundation[9] , the maximum testing load must be greater than twice of the pile's designed bearing capacity, and the maximum load provided by the counterforce equipment should not be less than 1.2 times of the maximum testing load.

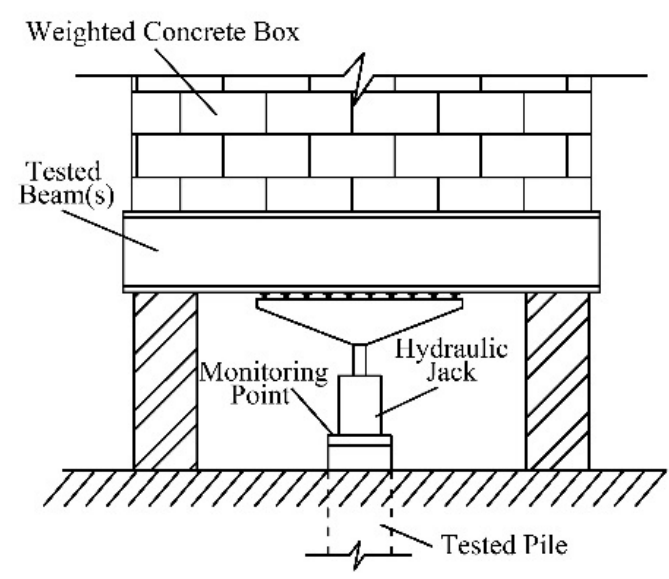

Fig 1. Weight Platform

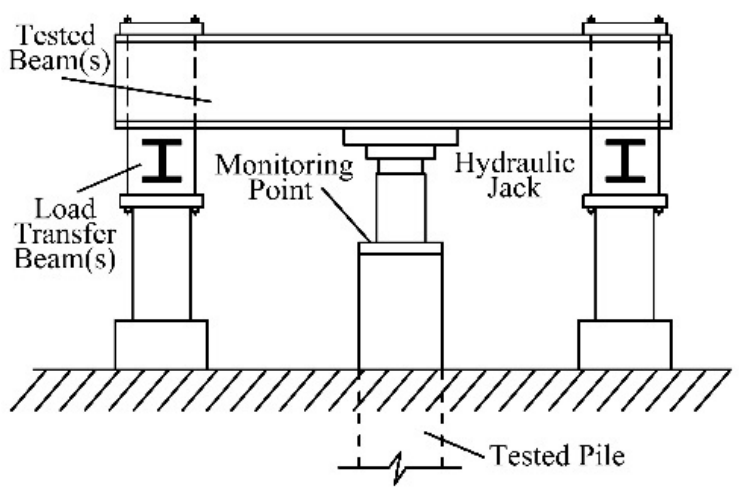

Fig 2. Anchor-Pile Beam

In the test, the pile will be loaded to the maximum testing load unless failure occurs first. The load is applied in increments of $10 \%$ of the maximum testing load, the first two increments can also be chosen as $20 \%$. In each load interval, the settlement of the pile is recorded at the $5^{\text {th }}, 15^{\text {th }}$ and $30^{\text {th }}$ minute, and then every 15 minutes thereafter. Each load increment will be maintained until the relative stable condition is met. The relative stable condition is: the axial settlement rate within the latest 15 minutes is lower than the one within the former 15 minutes. After completing the final load increment, remove the load in decrements of $20 \%$ of the maximum testing load. Each decrement is maintained for 15 minutes and the settlement is recorded at the $5^{\text {th }}$ and $15^{\text {th }}$ minute. When unloading is finished, the residual settlement is recorded at the $5^{\text {th }}, 15^{\text {th }}, 30^{\text {th }}$ minute, and then once every 30 minutes until 2 hours later.

\section{IoT-based Wireless Intelligent Static Load Testing Instrument}

\section{Working Mechanism}

The wireless intelligent static load testing instrument is composed of the major testing client, wireless laser displacement sensor, wireless hydraulic pressure controller, cloud platform software and mobile client software, its working mechanism is showed as Fig 3.

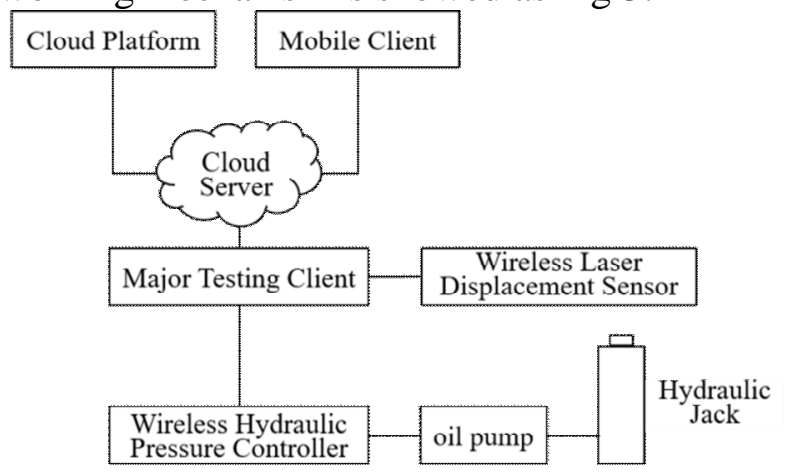

Fig 3. Working Mechanism of the Testing Instrument

There is a wireless automatic networking among the major testing client, displacement sensor and oil pressure controller. According to the instruction from the major testing client, the wireless hydraulic pressure controller controls the oil pump to lift the hydraulic jack to load or unload, while the wireless laser displacement sensor collects the settlement of the pile head and wirelessly transmits to the major testing client. Then the major testing client analyzes and stores the data, and uploads the data to cloud server for storage in the meantime. The cloud platform software and mobile client software obtain data 
from the cloud server, and achieve remote monitoring of experimental process and testing result, and real-time remote inquiry.

\section{The Major Testing Client}

The major testing client is composed of embedded micro control unit (MCU), data storage module, touch-sensitive display, wireless communication module, 4G communication module and backup power. The appearance and structure principle of the host are showed as Fig 4 and Fig 5. The data of pile top settlement is sent by the wireless laser displacement sensor, received by the wireless communication module, analyzed and managed by the embedded micro control unit (MCU), displayed and storage by the touch-sensitive display and data storage module, and uploaded to cloud server by $4 \mathrm{G}$ communication module. When sudden power failure occurs at site, the backup power ensures the data is collected and stored without interruption.

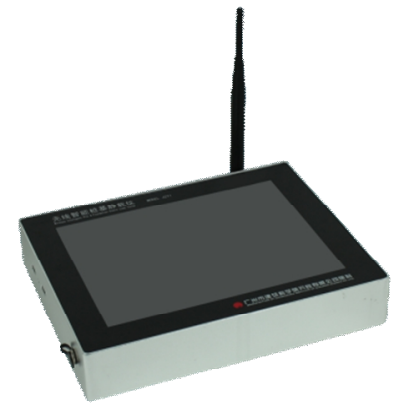

Fig 4. The Major testing client

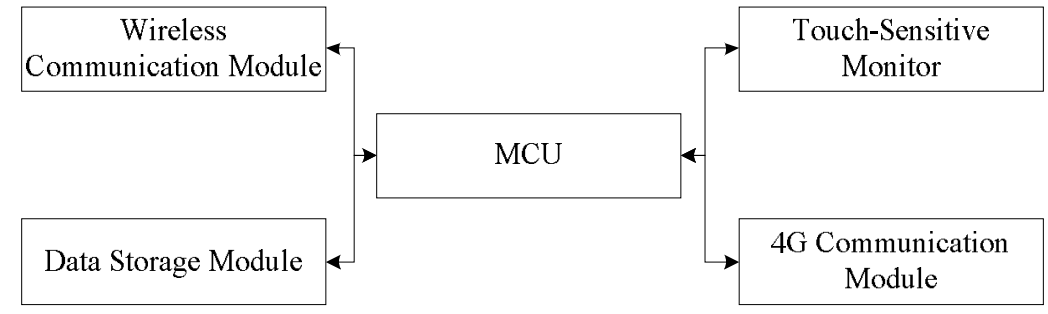

Fig 5. The Structure of the Major testing client

\section{The Wireless Laser Displacement Sensor}

The wireless laser displacement sensor (Fig 6) is used to measure the axial settlement of the pile head. The measuring range is $0 \sim 70 \mathrm{~mm}$, the linearity is $0.1 \% \mathrm{~F}$.S., which satisfies with the requirements of Chinese code [9]. The non-contact measurement of the pile head settlement can effectively avoid the interaction between the pile top and the benchmark through the sensor, hence improves the measurement accuracy. The sensor has high grade waterproof and dustproof design, which can effectively deal with the complex and harsh environment of the construction sites.

The wireless laser displacement sensor is composed of the laser range-finding module, A/D converting module, micro-processing module, LED display, wireless communication module and power module. The structure of the sensor is showed in Fig 7. Settlement of the pile head is measured by the laser range-finding module, and then the analog signal is converted to digital signal through the A/D converter. After processing by the micro-processing module, the data is displayed on the LED display, and sent to the major testing client through wireless communication module.

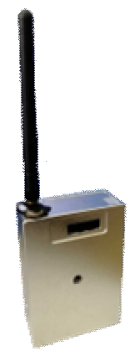

Fig 6. The Wireless Laser

Displacement Sensor



Fig 7. The Structure of the Wireless Laser Displacement Sensor

\section{The Wireless Hydraulic Pressure Controller}

The wireless hydraulic pressure controller (Fig 8) is used to control the electronic oil pump to load or unload and measure the oil pressure of the oil circuit. The measuring range is $0 \sim 150 \mathrm{MPa}$, the accuracy is $0.5 \%$ F.S., which satisfies with the requirements of Chinese code [9].

The wireless hydraulic pressure controller is composed of pressure sensor, A/D converting module, micro-processing module, control module and wireless communication module. The structure is showed in Fig 9. The pressure sensor is paralleled with the oil circuit, measures the oil pressure of the hydraulic jack, converts the analog signal to digital signal through the A/D converting module. After 
processing by the micro-processing module, the data is sent to the major testing client through wireless communication module. Then the instruction of the major testing client is accepted and control module controls the oil pump to load or unload.

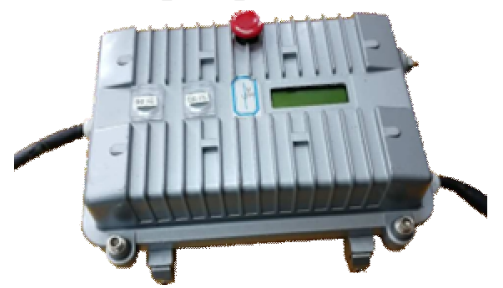

Fig 8.The Wireless Hydraulic Pressure Controller

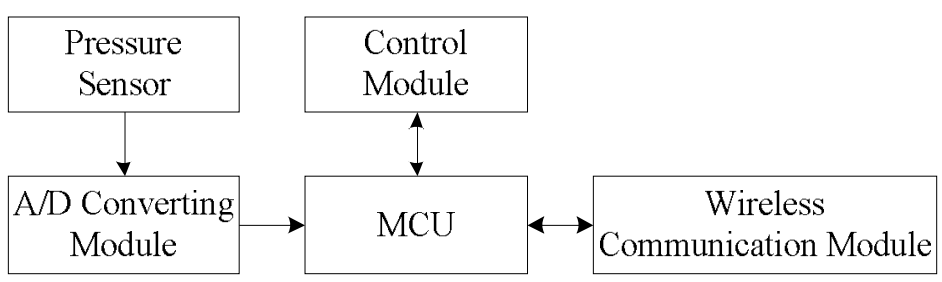

Fig 9.The Structure of the Wireless Hydraulic Pressure Controller

\section{The Cloud Platform Software}

The cloud platform software has the functions of project management, test data and report query, user management, etc. Users can remotely manage and maintain project information and test data, and monitor the ongoing static load tests through the cloud platform software. The interface of the cloud platform software is showed as Fig 10, composes of 4 functional modules including project overview, user management, platform setup, and about platform.

\section{The Mobile Client Software}

The Mobile Client Software is mainly used for remote monitoring and query of test data. Real-time data, history data and data curves can be accessed, the interface is showed as Fig 11.

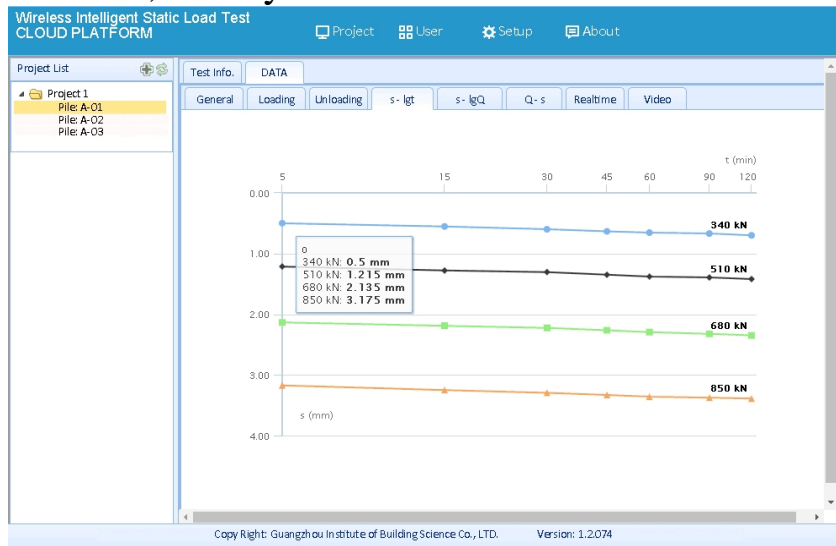

Fig 10. Cloud Platform

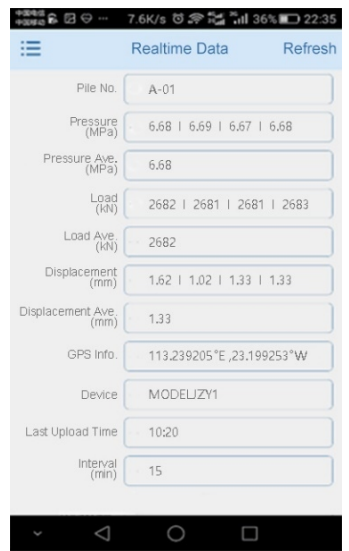

Fig 11. Mobile Client

\section{Field Test}

\section{General Situation of the Test}

The test was conducted within the construction site of a 4-storey office building located in Guangzhou, the bored pile coded as C-28 was chosen as the tested pile. The pile is $1200 \mathrm{~mm}$ in diameter, and $16.06 \mathrm{~m}$ the embedded to the ground. The strength grade of the pile's concrete is C30, the bearing course at the pile end is medium weathered compound gneiss. The $\mathrm{C}-28$ pile is designed to have an axial compressive bearing capacity of $6600 \mathrm{kN}$, so the maximum testing load in this test is $13200 \mathrm{kN}$. The weighted platform is consist of combined steel beams and weighted concrete box, and can provide a counterforce of over $15850 \mathrm{kN}$.

\section{The Layout of Settlement Monitoring Points}

Since the pile is greater than 500mm in diameter, according to the Chinese code[9], 4 settlement monitoring points are placed symmetrically on the 2 diagonals of the pile head (Fig 12). The settlement of the pile head is taken as the average of the displacements measured at all 4 points. At each monitoring point, as shown in Fig 13, a wireless laser displacement sensor is installed, and for comparison, a wired displacement sensor from one of the most widely used testing instrument is also installed on the next. The wired displacement sensor is $0 \sim 50 \mathrm{~mm}$, the linearity is $0.1 \% \mathrm{~F}$.S.. 




Fig 12.Layout of the Monitoring Points and Sensors

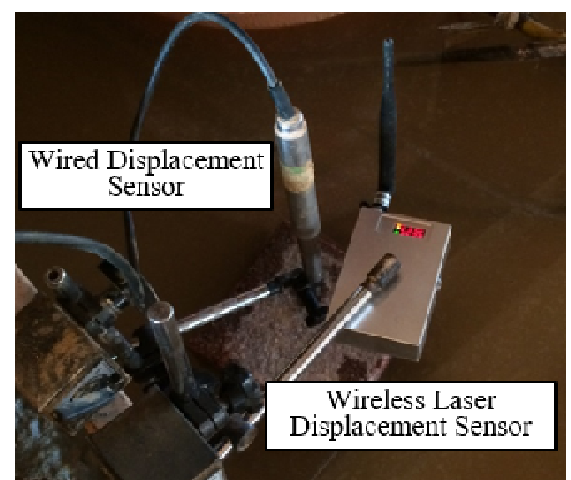

Fig 13. The Installation of Sensors

\section{Test Data Analysis}

The $Q-s$ curves and the $s$ - $\lg t$ curves collected by the wireless and wired sensors are shown in Fig 14 and Fig 15, all the curves collected by wireless laser displacement sensor coincide with the ones collected by the wired sensor. Table 1 shows the settlement of the pile head measured by both two types of sensors in each load level, the largest deviation is $-0.09 \mathrm{~mm}$. There are two causes of this deviation. Firstly, the places where the wireless and the wired sensors are installed cannot be exactly the same. Secondly, the theoretical error of the wireless sensor is : $\pm(70 \mathrm{~mm} \times 0.1 \%)= \pm 0.07 \mathrm{~mm}$, while the error of the wired sensor is: $\pm(50 \mathrm{~mm} \times 0.1 \%)= \pm 0.05 \mathrm{~mm}$, so theoretically, the relative error between these two sensors can be up to $\pm 0.12 \mathrm{~mm}$, which means that it is reasonable to have a deviation of $0.09 \mathrm{~mm}$.

Table 1. The Settlement of Pile Head

\begin{tabular}{ccccc}
\hline \multirow{2}{*}{ Period } & $\begin{array}{c}\text { Load } \\
(\mathbf{k N})\end{array}$ & \multicolumn{2}{c}{ Settlement of pile head (mm) } & $\begin{array}{c}\text { Deviation } \\
(\mathbf{m m})\end{array}$ \\
\cline { 3 - 4 } & Wireless ensor & Wired sensor & \\
\hline \multirow{3}{*}{ Loading } & 2640 & 1.29 & 1.33 & -0.04 \\
& 5280 & 2.62 & 2.58 & 0.04 \\
& 6600 & 3.55 & 3.61 & -0.06 \\
& 7920 & 4.40 & 4.44 & -0.04 \\
& 9240 & 5.08 & 5.17 & -0.09 \\
& 10560 & 5.97 & 5.99 & -0.02 \\
& 11880 & 6.80 & 6.75 & 0.05 \\
Unloading & 13200 & 7.71 & 7.77 & -0.06 \\
& 10560 & 7.64 & 7.66 & -0.02 \\
& 7920 & 6.90 & 6.88 & 0.02 \\
& 5280 & 5.75 & 5.74 & 0.01 \\
& 2640 & 4.34 & 4.34 & 0.00 \\
& 0 & 2.90 & 2.98 & -0.08 \\
\hline
\end{tabular}

When the maximum testing load is reached, the maximum settlement of the pile head measured by the wireless sensor is $7.11 \mathrm{~mm}$, and $7.77 \mathrm{~mm}$ by the wired sensor. In both cases, the rate of settlement can meet the relative stable condition, so the axial bearing capacity of the pile is $13200 \mathrm{kN}$. The remaining settlement after unloading is measured $2.90 \mathrm{~mm}$ by wireless sensors, so the rebound rate is $62.39 \%$. While in the case of wired sensors, the remaining settlement is measured to be $2.98 \mathrm{~mm}$, and the rebound rate is $61.65 \%$. The test results of the two instruments coincide with each other. 


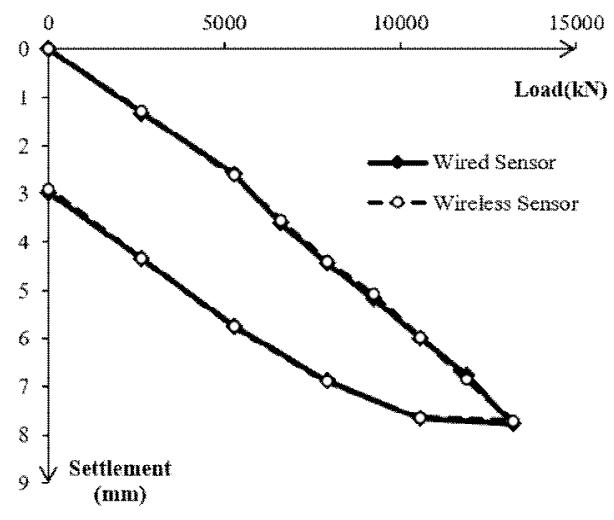

Fig 14. $Q-s$ Curve

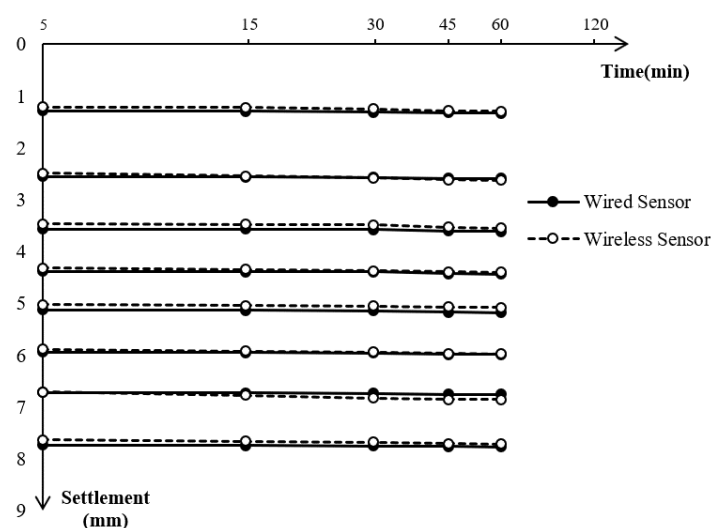

Fig 15. $s-\lg t$ Curve

\section{Conclusions}

In static load test conducted with the IoT-based testing instrument, the settlement of the pile head and the hydraulic pressure is measured by the wireless laser displacement sensor and the wireless hydraulic pressure controller, the data is transmitted wirelessly to the cloud platform and mobile client, in this case, the remote monitoring of the test procedure can be realized. All the devices of the testing instrument can be installed without wire arrangement, which is very convenient.

The deviation between the data collected by the wireless and wired sensors is relatively small. And the test result given by the IoT-based testing instrument coincides with the one of ordinary testing instrument. The comparison shows that it is appropriate to conduct the static load test with the IoT-based wireless intelligent static load testing instrument.

Both test results suggest that the axial compressive bearing capacity is $13200 \mathrm{kN}$, and the pile is of good quality.

\section{Acknowledgements}

This work was financially supported by the Guangdong Provincial Science and Technology Foundation (Grant No. 2016A040403067) and Foundation of Guangzhou Science Technology and Innovation Commission (Grant No. 201704020148).

\section{References}

[1] H.S. Hu, M.X. Tang and B.K. Liu: Guangzhou Architecture Vol. 6 (2012), p. 6-11(in Chinese)

[2] B.X Zhou: Guangzhou Architecture Vol. 4 (2015), p. 13-17(in Chinese)

[3] S. Moon.: Procedia Engineering Vol.196 (2017), p. 128-134

[4] J. Su, X.D. Huang, R.J. Chen: Guangzhou Architecture Vol. 2 (2017), p. 23-29(in Chinese)

[5] M.J. Chae, H.S. Yoo, J.Y. Kim, M.Y. Cho: Auto. in Constr. Vol.21 (2012), p.237-252

[6] L. Wang, Huazhong University of Science and Technology (2007) (in Chinese)

[7] J. Yu, M.G. Liu, H. Liang: Meas. Con. Tech. \& Instr. Vol. 10 (2010), p. 69-72(in Chinese)

[8] Jian Yu, Graduate University of Chinese Academy of Sciences (Institute of Rock and Soil Mechanics Academia Sinica) (2010) (in Chinese)

[9] Department of Housing and Urban-Rural Development of Guangdong: Code for Testing of Building Foundation (China Architecture \& Building Press, China, 2008). (in Chinese) 